\title{
Clinical parameters predicting survival duration after hepatectomy for intrahepatic cholangiocarcinoma
}

\author{
Bei-ge Jiang $M D^{1 *}$, Rui-liang Ge $M D^{1 *}$, Liang-liang Sun $M D^{2}$, Ming Zong $M D^{1}$, \\ Gong-tian Wei $\mathrm{MD}^{1}$, Yong-jie Zhang $\mathrm{MD}^{1 *}$
}

\begin{abstract}
B-g Jiang, R-1 Ge, L-1 Sun, M Zong, G-t Wei, Y-j Zhang. Clinical parameters predicting survival duration after hepatectomy for intrahepatic cholangiocarcinoma. Can J Gastroenterol 2011;25(11):603-608.
\end{abstract}

BACKGROUND: Currently, the most effective treatment for intrahepatic cholangiocarcinoma (ICC) is complete hepatic tumour excision. OBJECTIVE: To identify the clinical parameters associated with survival duration for ICC patients following hepatectomy, and to construct a mathematical model for predicting survival duration.

METHODS: Demographic data and clinical variables for 102 patients diagnosed with ICC, who underwent exploratory laparotomy at a single centre from July 1998 to December 2000 and were followed for an average of 24 months, were collected in 2011. Patients were randomly assigned into training $(n=76)$ and validation $(n=26)$ groups. Univariate and multivariate analyses were performed to identify factors associated with posthepatectomy survival duration.

RESULTS: Univariate analysis revealed that more than three lymph node metastases, a serum carbohydrate antigen 19-9 level $>37 \mathrm{U} / \mathrm{mL}$, stage IVa tumours, and intra- or perihepatic metastases were significantly associated with decreased survival duration. Curative resection was significantly associated with increased survival duration. A mathematical model incorporating parameters of age, sex, metastatic lymph node number, curative surgery, carbohydrate antigen 19-9 concentration, alpha-fetoprotein concentration, hepatitis B, TNM stage and tumour differentiation was constructed for predicting survival duration. For a survival duration of less than one year, the model exhibited 93.8\% sensitivity, $92.3 \%$ total accuracy and a positive predictive value of $93.8 \%$; for a survival duration of one to three years, the corresponding values were $80.0 \%, 69.2 \%$ and $57.1 \%$, repsectively.

CONCLUSIONS: The mathematical model presented in the current report should prove to be useful in the clinical setting for predicting the extent to which curative resection affects the survival of ICC patients, and for selecting optimal postoperative treatment strategies.

Key Words: Intrahepatic cholangiocarcinoma; Mathematical model; Prognosis; Survival duration prediction

Tntrahepatic or peripheral cholangiocarcinoma (ICC), a primary adenocarcinoma of the liver originating from the peripheral biliary epithelium, is the second most common primary liver cancer after hepatocellular carcinoma (1). ICC accounts for approximately $10 \%$ of primary liver malignancies, with a rapidly increasing incidence and mortality being reported in recent years $(2-4)$. The prognosis for patients with ICC is usually poor, with advanced tumours often observed due to the absence of early symptomatology. The median survival duration is less than six to nine months after diagnosis (5).

Presently, complete hepatic tumour excision is considered to be the most effective treatment for ICC (6-8). Although tumour resection has been shown to increase the probability of long-term survival for patients with ICC, the prognosis after surgery remains unsatisfactory due to early and frequent systemic spread of disease, and advanced

\author{
Les paramètres cliniques prédisant la durée de \\ survie après une hépatectomie consécutive à un \\ cholangiocarcinome intrahépatique
}

HISTORIQUE : Le traitement le plus efficace contre un cholangiocarcinome intrahépatique $(\mathrm{CCI})$ consiste à procéder à une excision complète de la tumeur hépatique.

OBJECTIF : Déterminer les paramètres cliniques associés à la durée de survie des patients atteints d'un CCI après une hépatectomie et construire un modèle mathématique pour prédire la durée de survie.

MÉTHODOLOGIE : En 2011, les chercheurs ont colligé les données démographiques et les variables cliniques de 102 patients ayant un diagnostic de CCI qui avaient subi une laparotomie exploratoire à un seul centre entre juillet 1998 et décembre 2000 et qui ont été suivis pendant une moyenne de 24 mois. Les patients ont été répartis au hasard entre un groupe de formation $(n=76)$ et un groupe de validation $(n=26)$. Des analyses univariées et multivariées ont permis d'établir les facteurs associés à la durée de survie après l'hépatectomie.

RÉSULTATS : L'analyse univariée a révélé que plus de trois métastases des ganglions lymphatiques, un taux d'antigène carbohydrate 19-9 sérique supérieur à $37 \mathrm{U} / \mathrm{mL}$, des tumeurs de phase IVa et des métastases intrahépatiques ou périhépatiques s'associaient de manière significative à une durée de survie réduite. Quant à la résection curative, elles'associait de manière significative à une durée de survie accrue. Un modèle mathématique intégrant les paramètres de l'âge, du sexe, du nombre de ganglions lymphatiques métastatiques, de la chirurgie curative, de la concentration d'antigènes carbohydrates 19-9, de la concentration d'alpha-fœetoprotéines, d'hépatite B, de classification TNM et de différenciation tumorale a été construit pour prédire la durée de survie. En cas de durée de survie de moins d'un an, le modèle affichait une sensibilité de 93,8 \%, une exactitude totale de $92,3 \%$ et une valeur prédictive positive de 93,8\%. En cas de durée de survie de un à trois ans, les valeurs correspondantes s'élevaient à $80,0 \%, 69,2 \%$ et $57,1 \%$, respectivement.

CONCLUSIONS : Le modèle mathématique présenté dans le présent rapport devrait se révéler utile en milieu clinique pour prédire la mesure selon laquelle une résection curative influe sur la survie des patients atteints d'un CCI et pour sélectionner les stratégies thérapeutiques postopératoires optimales.

tumour stage at the time of diagnosis $(5,8-15)$. In fact, a retrospective analysis by Suzuki et al (11) showed that the rate of lymph node (LN) metastasis ranges from $14 \%$ to $58 \%$, and that the rate of intrahepatic or satellite metastasis ranges from $26 \%$ to $58 \%$ in patients with ICC who had undergone surgical treatment. Even if surgical resection with complete dissection of LNs is achieved, postoperative survival is poor whenever multiple tumours, LN metastasis and/or vascular invasion occur; long-term survival of patients with these characteristics is rarely reported (6). Radiation and chemotherapy are alternative options for the treatment of ICC; however, neither has been demonstrated to be more efficacious than surgery for increasing long-term survival $(5,16)$.

Variables correlated with poor survival in patients with ICC have been identified in several previous reports. These variables include the presence of multiple tumours, extrahepatic bile duct involvement,

\footnotetext{
${ }^{1}$ Department of Laparoscopy, Eastern Hepatobiliary Surgery Hospital, Second Military Medical University; ${ }^{2}$ Department of Endocrinology 83 Metabolism,

Changzheng Hospital, Second Military Medical University, Shanghai, People's Republic of China. *Authors who contributed equally to this work

Correspondence: Dr Yong-jie Zhang, Department of Laparoscopy, Eastern Hepatobiliary Surgery Hospital, Second Military Medical University, Shanghai,

200438, People's Republic of China. Telephone 86-21-81875272, fax 86-21-55236653, e-mail jiang_beige@yahoo.com.cn

Received for publication September 19, 2010. Accepted April 16, 2011
} 
intrahepatic metastasis, metastasis to multiple LNs, disease stage, Union Internationale Contre le Cancer (UICC) pT, pN and pM factors, high serum carbohydrate antigen (CA) 19-9 level, histological type, positive histological margin, vascular invasion and the extent to which the tumour is susceptible to complete removal (ie, curative resection) $(8,9,12,17)$. The seventh edition of The American Joint Committee on Cancer Staging Manual provides approaches to predict survival for patients with ICC. To date, however, no predictive mathematical survival model that accounts for various risk factors has been provided. Therefore, the present retrospective study was undertaken to the assess risk factors for survival in patients with ICC who underwent hepatectomy, and to use such assessments in constructing a mathematical model for predicting survival.

\section{METHODS}

Subjects

The records of patients diagnosed with ICC from July 1998 to December 2000 who underwent exploratory laparotomy at the Eastern Hepatobiliary Surgery Hospital (Shanghai, People's Republic of China) were examined retrospectively in 2011. ICC was defined as cholangiocarcinoma arising from a segmental duct or from a more peripheral duct. Patients with hilar cholangiocarcinoma (Klatskin tumours) or mixed hepato/cholangiocellular carcinoma were excluded from analysis.

\section{Surgical procedures}

Surgical procedures included curative resection, noncurative resection and exploratory surgery without resection. Resection was considered to be curative when all detectable regional and invasive tumours were completely removed and confirmed by imaging examination. Areas of tumour dissection included the hepatic portal vein, hepatoduodenal ligament and LNs surrounding the pancreatic head. The margin of liver tumour resection was $\geq 1 \mathrm{~cm}$. Resection was considered to be noncurative when tumours were incompletely or partially removed due to adhesion to organs, involvement of major blood vessels or ongoing invasion, and when either partial clearing or no clearing of LNs was observed. Resection was not performed when very late stage or diffuse disease was revealed by exploratory surgery, indicating that attempts to remove the tumour(s) were not appropriate. The type of hepatectomy performed depended on both the tumour location and the mode of extension. Approximately 10 surgeons affiliated with the Eastern Hepatobiliary Surgery Hospital, with titles of Associate Professor, Associate Chief Physician or higher, were involved in the performance of these hepatectomies.

\section{Assessments}

To identify significant prognostic factors, pathological examinations were performed for all resected specimens by a single pathologist as described previously (18). All specimens were cut into serial slices $5 \mu \mathrm{m}$ thick, fixed in $10 \%$ formalin and subsequently embedded in paraffin. Paraffin-embedded tissues were stained with hematoxylin and eosin, periodic acid-Schiff and Alcian blue. The following parameters were assessed: LN metastasis, number of LNs with metastases, intrahepatic metastasis, vascular invasion, tumour size, degree of histological differentiation, resection margin status and liver cirrhosis. Tumours were staged (tumour, node, metastasis [TNM] I, II, IIIa, IIIb or IVa) according to the classification system of the UICC (fifth edition).

The concentrations of serum factors including CA 19-9, $\alpha$-fetoprotein (AFP), $\alpha$-L-fucosidase, carcinoembryonic antigen, $\gamma$-glutamyl transferase, alkaline phosphatase, total bilirubin and albumin were measured. Patient demographics and case history details (including postoperative survival duration) were recorded.

\section{Statistical analysis}

Continuous variables are presented as medians and interquartile ranges, whereas categorical variables are expressed as counts and percentages. To establish a predictive model of survival duration, all patients were randomly assigned to a training or validation group (3:1 ratio) using the random number generator provided with SPSS version 15.0 software (IBM Corporation, USA). Statistical comparisons between the training and validation groups were performed to confirm that no significant differences existed between the two randomly allocated groups. Continuous variables were compared using the Mann-Whitney $U$ test, whereas categorical variables were compared using the $\chi^{2}$ test or, when expected values of $20 \%$ of cells were less than 5, using Fisher's exact test. Univariate linear regression analysis was performed to identify factors that correlated with survival duration in the training group. Factors with $\mathrm{P}<0.1$ in this analysis were then entered into a multiple linear regression model. After a stepwise selective procedure, certain factors were eliminated from the backward multiple linear regression model. Thereafter, multiple linear regression analysis was performed to predict the duration of patient survival in the validation group. Additionally, due to their demographic importance, age and sex were included in the multiple linear regression analysis regardless of whether $\mathrm{P}<0.1$ was obtained for these variables in the univariate analysis. Actual and predicted survival durations for the validation group were classified as either $\leq 1$ or $>1$ year. The accuracy, sensitivity, specificity and positive predictive value of the constructed model were calculated, and $\mathrm{P}<0.05$ was considered to be statistically significant. All assessments were two sided and performed using SPSS software.

\section{RESULTS}

Demographics and clinical characteristics

A total of 102 patients ( 72 [71\%] men and 30 [29\%] women) ranging in age from 25 to 78 years, were included in the present study. It was the same cohort previously used to identify histopathological prognostic factors after hepatectomy for ICC (18). All patients were proven to have ICC either by pathological examination of surgical specimens or, in the case of 'nonsurgical' patients (ie, those who did not undergo resection after exploratory surgery), by using pathological examination of biopsy specimens. In both the training and validation groups, no significant association between hepatitis B and surgical curability was observed. The demographic and clinical characteristics of patients in both groups are presented in Table 1. No significant differences between the training and validation groups were observed. Slightly less than one-third of patients had no symptoms, whereas more than one-half experienced epigastric pain or distension. Approximately 7\%, 12\% and $43 \%$ of patients had a history of schistosomiasis, hepatic calculus and hepatitis B, respectively. With respect to TNM staging, 35.3\% of patients had tumours that were classified at or above stage IIIa. All survivors were followed for at least one month, with the median follow-up duration being slightly longer than one year. The overall one-, three- and fiveyear survival rates after hepatectomy were $57 \%, 26 \%$ and $17 \%$, respectively.

\section{Survival duration}

Univariate analysis: Table 2 summarizes the univariate analysis findings regarding survival duration for the 76 patients randomly assigned to the training group. Metastatic LN number, CA $19-9$ concentration, surgical curability, schistosomiasis, hepatitis B, TNM stage, albumin concentration, $\gamma$-glutamyl transferase concentration, carcinoembryonic antigen concentration, and intra- and perihepatic metastasis were significantly correlated with survival duration (all $\mathrm{P}<0.05$ ). Specifically, patients who had more than three LN metastases, serum CA 19-9 concentrations $>37 \mathrm{U} / \mathrm{mL}$, stage IVa tumours, or intra- or perihepatic metastases had significantly shorter survival durations. In contrast, survival duration was significantly increased in patients who underwent curative resection.

Multivariate analysis: The results of the multiple stepwise regression analysis are shown in Table 3. Increased survival duration was found to correlate significantly with the presence of well-differentiated tumours $(\mathrm{P}=0.002)$ and with curative surgery $(\mathrm{P}=0.007)$. Moreover, patients with serum CA $19-9$ concentrations $\geq 37 \mathrm{U} / \mathrm{mL}$, TNM stage above III, 
TABLE 1

Characteristics of patients who underwent hepatectomy for treatment of intrahepatic cholangiocarcinoma (n=102)

\begin{tabular}{|c|c|c|c|c|}
\hline Variable & Total $(n=102)$ & Training group $(n=76)$ & Validation group $(n=26)$ & $\mathbf{P}^{*}$ \\
\hline Age, years, median (interquartile range) & $52.0(43.0-62.3)$ & $51.0(40.0-60.0)$ & $52.0(43.0-63.8)$ & 0.575 \\
\hline Follow-up duration, months, median (interquartile range) & $14.5(7.0-35.3)$ & $15.5(7.8-36.8)$ & $14.5(9.0-36.0)$ & 0.716 \\
\hline Male sex & $72(70.6)$ & $53(69.7)$ & $19(73.1)$ & 0.747 \\
\hline None & $32(31.4)$ & $24(31.6)$ & $8(30.8)$ & \\
\hline Hepatomegaly & $2(2.0)$ & $2(2.6)$ & $0(0.0)$ & \\
\hline Epigastric pain or distention & $58(56.9)$ & $41(53.9)$ & $17(65.4)$ & \\
\hline Weight loss & $3(2.9)$ & $3(3.9)$ & $0(0.0)$ & \\
\hline Fever & $3(2.9)$ & $2(2.6)$ & $1(3.8)$ & \\
\hline History of schistosomiasis & $7(6.9)$ & $5(6.6)$ & $2(7.7)$ & 1.000 \\
\hline History of hepatic calculus & $12(11.8)$ & $9(11.8)$ & $3(11.5)$ & 1.000 \\
\hline History of hepatitis B & $44(43.1)$ & $34(44.7)$ & $10(38.5)$ & 0.650 \\
\hline Tumour stage (TNM) & & & & 0.456 \\
\hline IV & $6(5.9)$ & $3(3.9)$ & $3(11.5)$ & \\
\hline Surgical procedures & & & & 0.439 \\
\hline Noncurative resection $^{\dagger}$ & $37(36.3)$ & $30(39.5)$ & $7(26.9)$ & \\
\hline Curative resection ${ }^{\ddagger}$ & $57(55.9)$ & $41(53.9)$ & $16(61.5)$ & \\
\hline Exploratory only§ & $8(7.8)$ & $5(6.6)$ & $3(11.5)$ & \\
\hline
\end{tabular}

Data presented as $n(\%)$ unless otherwise indicated. *Calculated using the Mann-Whitney $U$ test for continuous variables, and by either the $\chi^{2}$ or Fisher's exact test for categorical variables; ${ }^{\dagger}$ Tumours were not completely removed and perihepatic lymph nodes were either partially cleared or were not cleared; ${ }^{\ddagger}$ All tumours were removed and perihepatic lymph nodes were cleared broadly; ${ }^{\S}$ Resection was not recommended to the patient because of diffused tumours or late stage of the disease. TNM Tumour, node, metastasis

and AFP values of $20 \mathrm{ng} / \mathrm{mL}$ to $400 \mathrm{ng} / \mathrm{mL}$ had shorter survival durations compared with those with CA 19-9 concentrations $\leq 37 \mathrm{U} / \mathrm{mL}$ $(\mathrm{P}<0.05)$, TNM stage I $(\mathrm{P}<0.001)$ and AFP concentrations $<20 \mathrm{ng} / \mathrm{mL}$ $(\mathrm{P}=0.002)$. It should be noted that the positive correlations of hepatitis $B$ and of perihepatic metastasis with survival duration observed in the univariate analysis were not observed in the multivariate analysis. In addition, metastatic LN number was found to correlate negatively with survival duration in the multivariate analysis; the presence of one or more tumours was associated with longer survival duration compared with the absence of tumours $(\mathrm{P}=0.021)$.

\section{Model for predicting survival}

The parameters chosen for inclusion in the equation for predicting survival following hepatectomy were age, sex, metastatic LN number, curative surgery, CA 19-9 concentration, AFP concentration, hepatitis B, TNM stage and tumour differentiation. Age, sex and CA 19-9 concentration were included in the model regardless of their statistical significance, whereas other variables were included because they were found to be significant. The established model is as follows:

Predicted log (survival duration [years]) $=1.26-0.06 \times$ (age between 41 and 65 years) $-0.26 \times$ (age greater than 65 years) +

$0.14 \times($ male sex $)+0.33 \times($ one or two $\mathrm{LNs})-0.03 \times$ [more than three LNs) $-0.23 \times(\mathrm{CA} 19-9 \geq 37 \mathrm{U} / \mathrm{mL})+0.66 \times$ (presence of strong differentiation) $-0.01 \times$ (poor differentiation) $+0.24 \times$ (curative surgery) $+0.23 \times$ (explored surgical curability) $+0.13 \times$ (hepatitis B -0.17 [TNM stage II] $-0.51 \times$ [TNM stage at III or above) $-0.40 \times$ (AFP concentration between

20-400 pg/mL) - $0.05 \times($ AFP concentration $>400 \mathrm{pg} / \mathrm{mL})$.

In this model, all variables were categorical and each received a value of ' 1 ' when exhibited by the patient.

The findings summarizing the accuracy of this predictive model are shown in Tables 4 and 5. For predicting survival duration longer than one year, the sensitivity, specificity, overall accuracy and positive predicted values were $93.8 \%, 90.0 \%, 92.3 \%$ and $93.8 \%$, respectively
(Table 4). However, the sensitivity, specificity, overall accuracy and positive predictive values for predicting survival duration between one and three years were each considerably reduced (Table 5).

The predicted survival time based on the model described above, and the real survival time for all patients who died $(n=89)$ are shown in Figure 1. Regression analysis revealed that predicted survival (months $)=0.47 \times$ actual survival months $+8.2(\gamma=0.62 ; \mathrm{P}<0.0001)$ for these patients. The predicted survival among patients who survived no longer than 24 months $(n=60)$ was closer to the actual survival time; for this group, predicted survival (months) $=0.92 \times$ survival months $+3.75(\gamma=0.63 ; \mathrm{P}<0.001)$. These findings indicate that prediction was better when the survival time was no longer than two years.

\section{DISCUSSION}

In the present study, we retrospectively analyzed the records of patients who underwent hepatectomy for the treatment of ICC to assess factors associated with survival duration. These factors were then incorporated into a mathematical model for predicting survival duration.

The factors included in the equation to predict survival duration were age, sex, metastatic LN number, curative surgery, CA 19-9 concentration, AFP concentration, hepatitis B, TNM stage and tumour differentiation. Use of this equation should, therefore, permit clinicians to make a prognosis based on preoperative (eg, laboratory tests, patient-related circumstances) and intraoperative tumour characteristics. Although similar to TNM staging, mathematical modelling is more specific because each factor is given its own clear weight. Of particular importance is the capability of this formula to predict the extent to which curative hepatectomy affects survival duration. As shown in the present report, use of this model revealed that surgical curability positively and substantially contributes to survival, and indicates that management of ICC should include curative hepatectomy if possible. This mathematical model may also be helpful for evaluating the efficacy of new treatments. For example, should survival duration following the use of updated operative techniques, or new postoperative chemotherapies or radiation treatments prove to be longer than 
TABLE 2

Summary of the univariate linear regression analysis findings regarding survival duration of patients in the training group who underwent hepatectomy for treatment of intrahepatic cholangiocarcinoma* $(n=76)$

\begin{tabular}{|c|c|c|c|c|}
\hline Variable & Beta & SE & $95 \% \mathrm{Cl}$ & $\mathbf{P}$ \\
\hline \multicolumn{5}{|l|}{ Age, years } \\
\hline$<40$ & Ref & - & - & - \\
\hline $41-65$ & 0.08 & 0.14 & -0.19 to 0.36 & 0.552 \\
\hline$>65$ & -0.05 & 0.18 & -0.42 to 0.31 & 0.774 \\
\hline \multicolumn{5}{|l|}{ Sex } \\
\hline Female & Ref & - & - & - \\
\hline Male & 0.11 & 0.12 & -0.12 to 0.35 & 0.337 \\
\hline \multicolumn{5}{|l|}{ Metastatic lymph nodes, $\mathrm{n}$} \\
\hline 0 & Ref & - & - & - \\
\hline $1-2$ & -0.03 & 0.17 & -0.37 to 0.31 & 0.869 \\
\hline$\geq 3$ & -0.38 & 0.14 & -0.66 to -0.09 & $0.011^{\dagger}$ \\
\hline \multicolumn{5}{|l|}{ CA $19-9 \mathrm{U} / \mathrm{mL}$} \\
\hline$<37$ & Ref & - & - & - \\
\hline$\geq 37$ & -0.40 & 010 & -0.60 to -0.21 & $<0.001^{\dagger}$ \\
\hline \multicolumn{5}{|l|}{ Differentiation } \\
\hline Well & 0.49 & 0.28 & -0.07 to 1.04 & 0.083 \\
\hline Moderate & Ref & - & - & - \\
\hline Poor & 0.12 & 0.11 & -0.10 to 0.33 & 0.291 \\
\hline Positive lymph node & -0.24 & 0.12 & -0.48 to 0.01 & 0.051 \\
\hline Intrahepatic metastasis & -0.26 & 0.11 & -0.47 to -0.05 & $0.018^{\dagger}$ \\
\hline Perihepatic metastasis & -0.35 & 0.14 & -0.64 to -0.07 & $0.016^{\dagger}$ \\
\hline \multicolumn{5}{|l|}{ Surgical procedures } \\
\hline Noncurative resection ${ }^{\ddagger}$ & Ref & - & - & - \\
\hline Curative resection $\S$ & 0.42 & 0.10 & 0.22 to 0.62 & $<0.001^{\dagger}$ \\
\hline Exploratory only & -0.07 & 0.20 & -0.48 to 0.33 & 0.723 \\
\hline \multicolumn{5}{|l|}{ Tumour size, cm } \\
\hline$<3$ & Ref & - & - & - \\
\hline $3-5$ & -0.20 & 0.24 & -0.67 to 0.27 & 0.400 \\
\hline $5-10$ & -0.46 & 0.26 & -0.97 to 0.05 & 0.076 \\
\hline Schistosomiasis & -0.51 & 0.21 & -0.93 to -0.09 & $0.018^{\dagger}$ \\
\hline Hepatic calculus & -0.17 & 0.17 & -0.50 to 0.16 & 0.305 \\
\hline HBsAg positive & 0.24 & 0.11 & 0.29 to 0.45 & $0.026^{\dagger}$ \\
\hline Hepatic cirrhosis & 0.07 & 0.11 & -0.14 to 0.29 & 0.495 \\
\hline \multicolumn{5}{|l|}{ Tumour stage TNM } \\
\hline I & Ref & - & - & - \\
\hline II & -0.34 & 0.12 & -0.57 to -0.11 & $0.004^{\dagger}$ \\
\hline III+IV & -0.72 & 0.12 & -0.96 to -0.49 & $<0.001^{\dagger}$ \\
\hline \multicolumn{5}{|l|}{ Total bilirubin, $\mu \mathrm{mol} / \mathrm{L}$} \\
\hline$<20$ & Ref & - & - & - \\
\hline$\geq 20$ & -0.32 & 0.18 & -0.69 to -0.04 & 0.084 \\
\hline \multicolumn{5}{|l|}{ Albumin, g/L } \\
\hline$\geq 34$ & Ref & - & - & - \\
\hline$<34$ & 0.32 & 0.18 & -0.04 to 0.69 & $0.031^{\dagger}$ \\
\hline \multicolumn{5}{|l|}{ GGT, U/L } \\
\hline$<50$ & Ref & - & - & - \\
\hline$\geq 50$ & -0.25 & 0.11 & -0.47 to -0.03 & $0.028^{\dagger}$ \\
\hline \multicolumn{5}{|l|}{ ALP, U/L } \\
\hline$<140$ & Ref & - & - & - \\
\hline$\geq 140$ & -0.10 & 0.11 & -0.33 to 0.12 & 0.177 \\
\hline \multicolumn{5}{|l|}{ AFU, U/L } \\
\hline$<10.2$ & Ref & - & - & - \\
\hline$\geq 10.2$ & 0.07 & 0.13 & -0.2 to 0.36 & 0.624 \\
\hline \multicolumn{5}{|l|}{ CEA, ng/mL } \\
\hline$<10$ & Ref & - & - & - \\
\hline$\geq 10$ & -0.36 & 0.14 & -0.63 to -0.09 & $0.011^{\dagger}$ \\
\hline \multicolumn{5}{|l|}{ AFP, ng/mL } \\
\hline$<20$ & Ref & - & - & - \\
\hline $20-400$ & -0.26 & 0.15 & -0.56 to 0.05 & 0.097 \\
\hline$>400$ & 0.14 & 0.18 & -0.20 to 0.49 & 0.413 \\
\hline
\end{tabular}

TABLE 2 - CONTINUED

\begin{tabular}{lcccc}
\hline Variable & Beta & SE & $95 \% \mathrm{Cl}$ & $\mathbf{P}$ \\
\hline Type of tumour growth & & & & \\
$\quad$ Normal & Ref & - & - & - \\
Infiltration & 0.02 & 0.12 & -0.26 to 0.23 & 0.895 \\
Multifocus & 0.08 & 0.15 & -0.22 to 0.38 & 0.594 \\
\hline
\end{tabular}

*Determined using linear regression analysis. Log transformation was applied to the survival period; 'Statistically significant survival duration (ie, $P<0.05$ );

${ }^{\ddagger}$ Tumours were not completely removed and perihepatic lymph nodes were either partially cleared or were not cleared; ${ }^{\S}$ All tumours were removed and perihepatic lymph nodes were cleared broadly; "Resection was not recommended to the patient because of diffused tumours or late stage of the disease. AFP Alpha-fetoprotein; AFU Arbitrary fluorescence units; ALP Alkaline phosphatase; CA Carbohydrate cell surface antigen; CEA Carcinoembryonic antigen; GGT Gamma-glutamyl transferase; HBSAg Hepatitis B surface antigen; Ref Reference; TNM Tumour, node, metastasis

TABLE 3

Summary of the multivariate analysis findings regarding survival duration for patients in the training group who underwent hepatectomy for treatment of intrahepatic cholangiocarcinoma* $(n=76)$

\begin{tabular}{|c|c|c|c|c|}
\hline & Beta & SE & $95 \% \mathrm{Cl}$ & $\mathbf{P}$ \\
\hline \multicolumn{5}{|l|}{ Age, years } \\
\hline$<40$ & Ref & - & - & - \\
\hline $41-65$ & -0.06 & 0.11 & -0.28 to 0.15 & 0.573 \\
\hline$>65$ & -0.26 & 0.15 & -0.55 to 0.04 & 0.084 \\
\hline \multicolumn{5}{|l|}{ Sex } \\
\hline Female & Ref & - & - & - \\
\hline Male & 0.14 & 0.08 & -0.03 to 0.30 & 0.115 \\
\hline \multicolumn{5}{|l|}{ Metastatic lymph nodes, $\mathrm{n}$} \\
\hline 0 & Ref & - & - & - \\
\hline $1-2$ & 0.33 & 0.14 & 0.05 to 0.61 & $0.021^{\dagger}$ \\
\hline$\geq 3$ & -0.03 & 0.14 & -0.31 to 0.26 & 0.856 \\
\hline \multicolumn{5}{|l|}{ CA 19-9, U/mL } \\
\hline$<37$ & Ref & - & - & - \\
\hline$\geq 37$ & -0.23 & 0.09 & -0.40 to -0.05 & $0.012^{\dagger}$ \\
\hline \multicolumn{5}{|l|}{ Differentiation } \\
\hline Well & 0.66 & 0.20 & 0.25 to 1.07 & $0.002^{\dagger}$ \\
\hline Moderate & Ref & - & - & - \\
\hline Poor & 0.01 & 0.08 & -0.16 to 0.16 & 0.995 \\
\hline \multicolumn{5}{|l|}{ Surgical procedures } \\
\hline Noncurative resection ${ }^{\ddagger}$ & Ref & - & - & - \\
\hline Curative resection $\S$ & 0.24 & 0.08 & 0.07 to 0.40 & $0.007^{\dagger}$ \\
\hline Exploratory only ${ }^{\pi}$ & 0.23 & 0.17 & -0.12 to 0.58 & 0.189 \\
\hline \multicolumn{5}{|l|}{ Hepatitis B } \\
\hline No & Ref & - & - & - \\
\hline Yes & 0.13 & 0.09 & -0.04 to 0.31 & 0.126 \\
\hline \multicolumn{5}{|l|}{ TNM stage } \\
\hline 1 & Ref & - & - & - \\
\hline II & -0.17 & 0.11 & -0.38 to 0.05 & 0.124 \\
\hline $\mathrm{III+IV}$ & -0.51 & 0.13 & -0.78 to -0.24 & $<0.001^{\dagger}$ \\
\hline \multicolumn{5}{|l|}{ Alpha fetoprotein, ng/mL } \\
\hline$<20$ & Ref & - & - & - \\
\hline 20-400 & -0.40 & 0.12 & -0.64 to -0.16 & $0.002^{\dagger}$ \\
\hline$>400$ & -0.05 & 0.14 & -0.33 to 0.23 & 0.710 \\
\hline
\end{tabular}

*Multiple stepwise regression was used. Log transformation was applied to survival duration; 'Statistically significant survival duration (ie, $P<0.05$ ); ${ }^{\ddagger}$ Tumours were not completely removed and perihepatic lymph nodes were either partially cleared or were not cleared; $\varsigma^{\S}$ All tumours were removed and perihepatic lymph nodes were cleared broadly; "Resection was not recommended to the patient because of diffused tumours or late stage of the disease. CA Carbohydrate cell surface antigen; Ref Reference: TNM Tumour, node, metastasis 
TABLE 4

Accuracy of predicting a survival duration of longer than one year for subjects in the validation group $(n=26)$

\begin{tabular}{lcc}
\hline & \multicolumn{2}{c}{ Actual survival duration, years } \\
\cline { 2 - 3 } Predicted result, years & $\mathbf{\leq 1}(\mathrm{n}=\mathbf{1 0})$ & $\mathbf{1}(\mathrm{n}=\mathbf{1 6})$ \\
\hline$\leq 1$ & 9 & 1 \\
$>1$ & 1 & 15 \\
Sensitivity, \% & 93.8 & - \\
Specificity, \% & 90.0 & - \\
Total accuracy, \% & 92.3 & - \\
Positive predictive value, \% & 93.8 & - \\
\hline
\end{tabular}

TABLE 5

Accuracy of predicting survival duration of between one and three year(s) for subjects in the validation group $(n=26)$

\begin{tabular}{lcc}
\hline & \multicolumn{2}{c}{ Actual survival duration, years } \\
\cline { 2 - 3 } Predicted result (years) & $<\mathbf{1}$ or $>\mathbf{3}(\mathbf{n}=\mathbf{1 5})$ & $\mathbf{1 - 3}(\mathbf{n}=\mathbf{1 1})$ \\
\hline$<1$ or $>3$ & 10 & 2 \\
$1-3$ & 6 & 8 \\
Sensitivity, \% & 80.0 & - \\
Specificity, \% & 62.5 & - \\
Total accuracy, \% & 69.2 & - \\
Positive predictive value, $\%$ & 57.1 & - \\
\hline
\end{tabular}

initially calculated, such techniques or treatments can be considered to be effective or improved. In some cases, good survival prediction may result in patients receiving more effective hospice care.

The presence of intrahepatic metastasis is reported to represent an important factor affecting the prognosis of patients with ICC $(11,13,14,19,20)$. For example, Suzuki et al (11) found that none of the six patients with intrahepatic metastasis in their study survived beyond 14 months. Furthermore Endo et al (19), who evaluated approximately 300 patients with ICC, observed that those with multiple hepatic tumours demonstrated significantly poorer rates of disease-free survival. In agreement with these findings, the univariate analysis performed in the present study showed that intrahepatic metastasis is significantly associated with decreased survival of patients with ICC.

Regional LN metastasis is another factor reported to be significantly associated with poor outcome in several ICC-related studies $(8,10,13,14,21)$. Nakagawa et al (17) concluded that prognosis and survival were related not only to the presence of extrahepatic LN metastasis, but also to the number of LN metastases. While some authors have suggested that LN dissection is necessary to prolong survival in patients with $\operatorname{ICC}(8,10,17)$, others have argued that this procedure does not appear to markedly influence long-term survival $(13,14,22)$. In agreement with the latter observations, the multivariate analysis performed in the present study suggests that the number of LN metastases does not significantly influence survival. The difference between these findings and those of other studies $(8,10,17)$ may reflect differences in tumour stages and/or in the ability to perform radical surgery.

It should be noted that reports of patients surviving more than six years $(6,7,23)$ or even up to seven years (24) after LN dissection, without tumour recurrence have been published. Okami et al (25) used advanced molecular techniques to demonstrate the presence of extrahepatic LN micrometastases in patients with bile duct tumours that cannot be detected by traditional pathological examinations, suggesting that extensive lymphadenectomy would be of benefit in such patients. Clearly, some patients with extrahepatic LN metastases can obtain the same benefit from surgical treatment after lymphadenectomy as can those without such metastases.

The present study has several limitations that should be noted, the most obvious of which is the relatively short follow-up duration (mean of 22 months). It is necessary to ascertain whether the findings

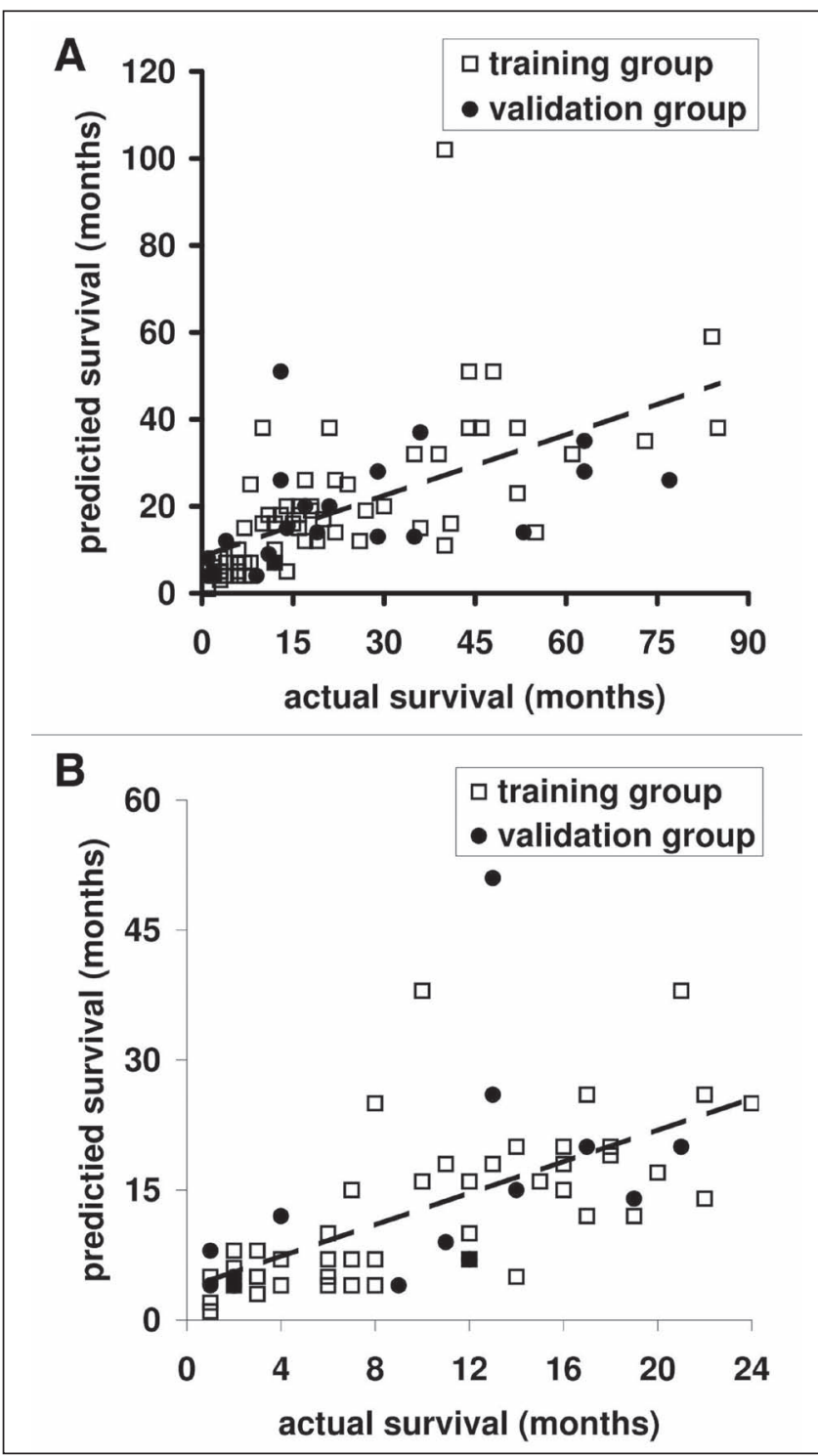

Figure 1) Comparison of predicted survival time with actual survival time. Predictions were made for patients who died during follow-up including 65 patients in the training group and 24 patients in the validation group (A). The plot of predicted survival time against real survival time reveals that predictive survival $=0.47 \times$ actual survival time $+8.24 \quad(\gamma=0.62$; $P<0.001)$. However, for patients with a survival time of no more than two years $(\mathbf{B})(n=60)$, predicted survival $=0.92 \times$ actual survival time + $3.75(\gamma=0.63 ; P<0.001)$

presented are relevant for longer follow-up durations. It is also acknowledged that the sample size was relatively small for a study of this nature. Accordingly, the decreased predictive accuracy of the model for longer survival durations may have been a consequence of inadequate sample size. Larger scale studies of longer duration are, therefore, planned to confirm the findings presented in the current report.

ACKNOWLEDGEMENT: This research was supported by a grant from the National Natural Science Foundation of China (Project 30872989).

CONFLICTS OF INTEREST: The authors have no conflicts of interest to declare. 


\section{REFERENCES}

1. de Groen PC, Gores GJ, Larusso NF, et al. Biliary tract cancers. N Engl J Med 1999;341:1368-78.

2. Shaib Y, El-Serag HB. The epidemiology of cholangiocarcinoma. Semin Liver Dis 2004;24:115-25.

3. Patel T. Worldwide trends in mortality from biliary tract malignancies. BMC Cancer 2002;2:10.

4. Khan SA, Taylor-Robinson SD, Toledano MB, et al. Changing international trends in mortality rates for liver, biliary and pancreatic tumours. J Hepatol 2002;37:806-13.

5. Lang H, Sotiropoulos GC, Fruhauf NR, et al. Extended hepatectomy for intrahepatic cholangiocellular carcinoma (ICC): When is it worthwhile? Single center experience with 27 resections in 50 patients over a 5-year period. Ann Surg 2005;241:134-43.

6. Akatsu T, Shimazu M, Kawachi S, et al. Long-term survival of intrahepatic cholangiocarcinoma with hilar lymph node metastasis and portal vein involvement. Hepatogastroenterology 2005;52:603-5.

7. Asakura $H$, Ohtsuka M, Ito $H$, et al. Long-term survival after extended surgical resection of intrahepatic cholangiocarcinoma with extensive lymph node metastasis. Hepatogastroenterology 2005;52:722-4.

8. Kawarada Y, Yamagiwa K, Das BC. Analysis of the relationships between clinicopathologic factors and survival time in intrahepatic cholangiocarcinoma. Am J Surg 2002;183:679-85.

9. Ohtsuka M, Ito H, Kimura F, et al. Results of surgical treatment for intrahepatic cholangiocarcinoma and clinicopathological factors influencing survival. Br J Surg 2002;89:1525-31.

10. Nakagohri T, Asano T, Kinoshita H, et al. Aggressive surgical resection for hilar-invasive and peripheral intrahepatic cholangiocarcinoma. World J Surg 2003;27:289-93.

11. Suzuki S, Sakaguchi T, Yokoi Y, et al. Clinicopathological prognostic factors and impact of surgical treatment of mass-forming intrahepatic cholangiocarcinoma. World J Surg 2002;26:687-93.

12. Weber SM, Jarnagin WR, Klimstra D, et al. Intrahepatic cholangiocarcinoma: Resectability, recurrence pattern, and outcomes. J Am Coll Surg 2001;193:384-91.

13. Uenishi T, Hirohashi K, Kubo S, et al. Clinicopathologic features in patients with long-term survival following resection for intrahepatic cholangiocarcinoma. Hepatogastroenterology 2003;50:1069-72.
14. Shimada M, Yamashita Y, Aishima S, et al. Value of lymph node dissection during resection of intrahepatic cholangiocarcinoma. Br J Surg 2001;88:1463-6.

15. Isaji S, Kawarada Y, Taoka H, et al. Clinicopathological features and outcome of hepatic resection for intrahepatic cholangiocarcinoma in Japan. J Hepatobiliary Pancreat Surg 1999;6:108-16.

16. Jan YY, Yeh CN, Yeh TS, et al. Clinicopathological factors predicting long-term overall survival after hepatectomy for peripheral cholangiocarcinoma. World J Surg 2005;29:894-8.

17. Nakagawa T, Kamiyama T, Kurauchi N, et al. Number of lymph node metastases is a significant prognostic factor in intrahepatic cholangiocarcinoma. World J Surg 2005;29:728-33.

18 Jiang BG, Sun LL, Yu WL, et al. Retrospective analysis of histopathologic prognostic factors after hepatectomy for intrahepatic cholangiocarcinoma. Cancer J 2009;15:257-61.

19. Endo I, Gonen M, Yopp AC, et al. Intrahepatic cholangiocarcinoma: Rising frequency, improved survival, and determinants of outcome after resection. Ann Surg 2008;248:84-96.

20. Nathan H, Aloia TA, Vauthey JN, et al. A proposed staging system for intrahepatic cholangiocarcinoma. Ann Surg Oncol 2009;16:14-22.

21. Paik KY, Jung JC, Heo JS, et al. What prognostic factors are important for resected intrahepatic cholangiocarcinoma? J Gastroenterol Hepatol 2008;23:766-70.

22. Inoue K, Makuuchi M, Takayama T, et al. Long-term survival and prognostic factors in the surgical treatment of mass-forming type cholangiocarcinoma. Surgery 2000;127:498-505.

23. Yamamoto M, Takasaki K, Imaizumi T, et al. A long-term survivor of intrahepatic cholangiocarcinoma with lymph node metastasis: A case report. Jpn J Clin Oncol 2002;32:206-9.

24. Uenishi T, Yamazaki O, Horii K, et al. A long-term survivor of intrahepatic cholangiocarcinoma with paraaortic lymph node metastasis. J Gastroenterol 2006;41:391-2.

25. Okami J, Dohno K, Sakon M, et al. Genetic detection for micrometastasis in lymph node of biliary tract carcinoma. Clin Cancer Res 2000;6:2326-32. 


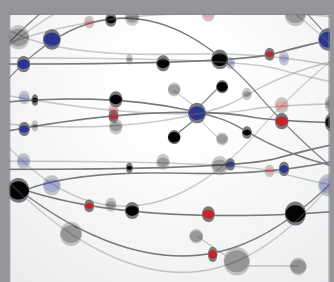

The Scientific World Journal
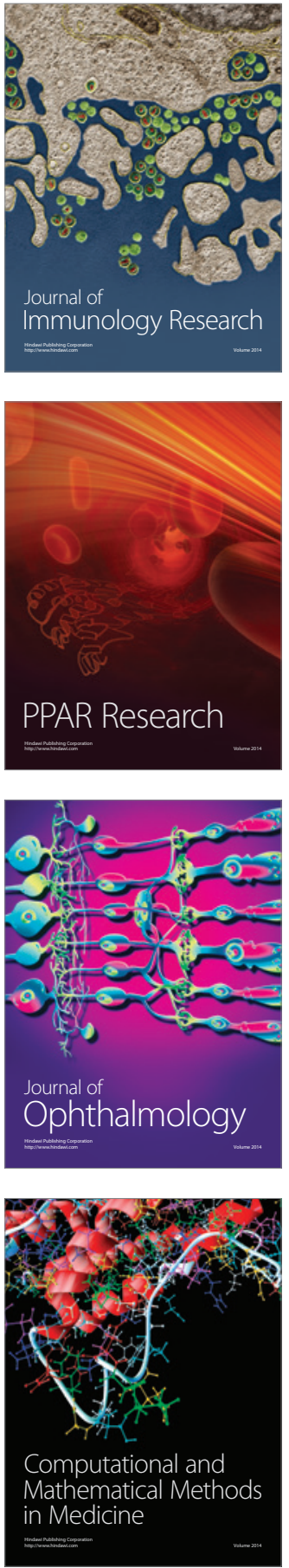

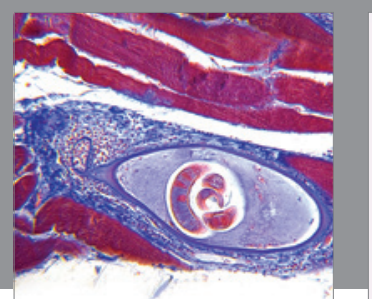

Gastroenterology Research and Practice

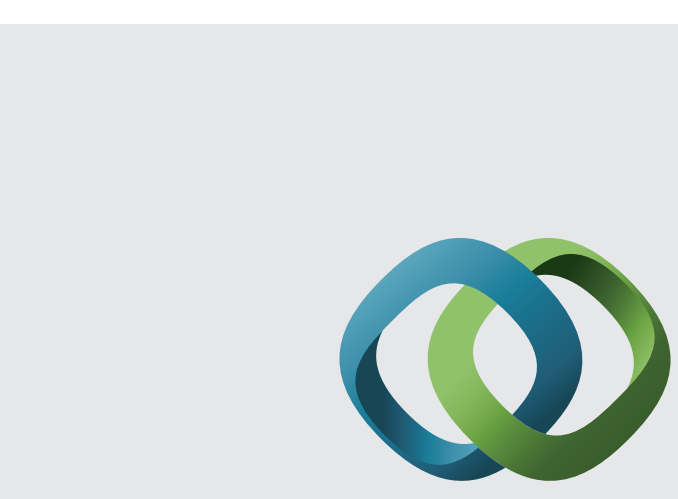

\section{Hindawi}

Submit your manuscripts at

http://www.hindawi.com
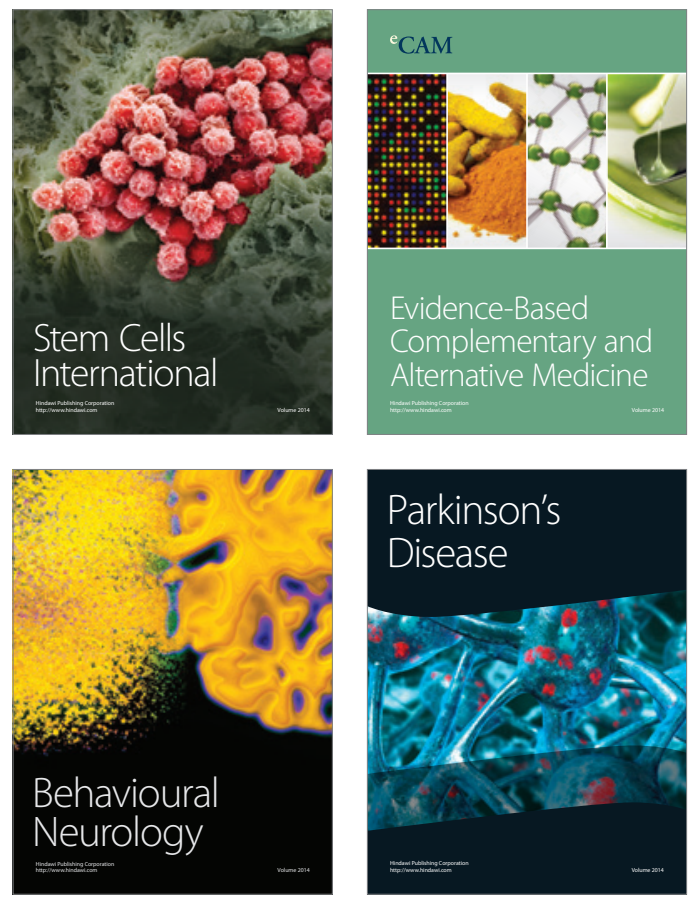
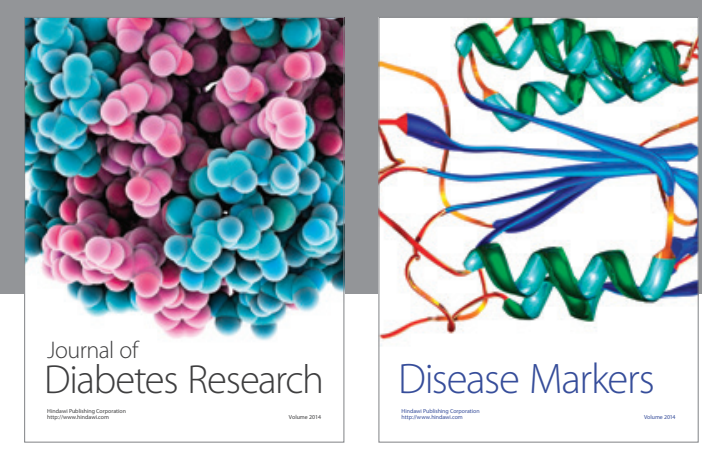

Disease Markers
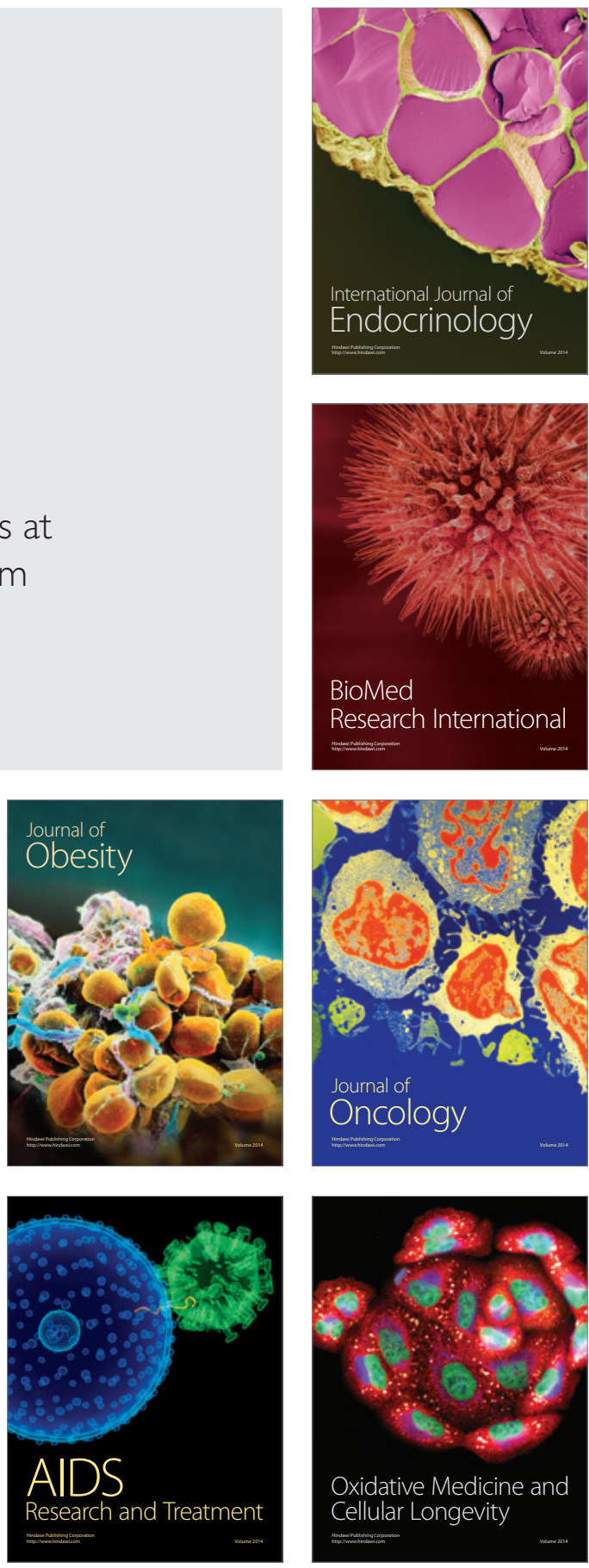